\title{
Validación del "test del aire" para detectar el shunt inducido por atelectasias en anestesia pediátrica
}

\author{
Venturín N. ${ }^{1}$, Rudzik N. ${ }^{1}$, Gerez S. ${ }^{1}$, Santanera B. ${ }^{1}$, Portela F. ${ }^{1}$, Viotti F. ${ }^{1}$, Acosta MC. ${ }^{1}$, Tusman G. ${ }^{1}$ \\ 1 Hospital Privado de Comunidad, Mar del Plata, Argentina.
}

Objetivo: Las atelectasias pulmonares perioperatorias es un problema común en anestesia que está relacionado con complicaciones pulmonares postoperatorias. Dichas atelectasias crean un efecto shunt que obliga al uso de fracción inspirada de oxígeno ( $\mathrm{FiO} 2$ ) altas para evitar la hipoxemia. El principal problema del uso de FiO2 altas es que la hemoglobina se satura al máximo y pierde su habilidad para detectar problemas en la oxigenación de la sangre arterial. El "Test del Aire" es una técnica sencilla ideada para detectar shunt en presencia de una fracción inspirada de oxígeno (FiO2) elevada. El objetivo de esta presentación es validar la precisión de dicho test para detectar el shunt inducido por las atelectasias intraoperatorias en pacientes pediátricos anestesiados.

Métodos: Efectuamos un análisis retrospectivo de 88 pacientes pediátricos anestesiados que presentaban valores basales de $\mathrm{SpO} 2 \geq 97 \%$. El Test del Aire se realizó luego de la intubación traqueal y consistió en un descenso abrupto de la $\mathrm{FiO} 2$, de $50 \%$ a 21\%, durante 5 minutos. Un valor de $\mathrm{SpO} 2 \leq 96 \%$ respirando aire ambiente representa un shunt patológico mayor al 10\%. El test fue positivo cuando la $\mathrm{SpO} 2 \leq 96 \%$ y negativo cuando la $\mathrm{SpO} 2$ se mantuvo $\geq 97 \%$. Las atelectasias se diagnosticaron con ultrasonido pulmonar realizado durante el test usando una sonda lineal (9-12 $\mathrm{MhZ}$ ) e investigando cada hemitórax en sus áreas ventrales, laterales y posteriores. Se definió las atelectasias a las consolidaciones subpleurales con presencia de broncogramas aéreos.

Resultados: 67 pacientes presentaron un test positivo y 21 un test negativo. La SpO2 basal fue similar en los pacientes con test positivo $(98,6 \pm 0,6 \%)$ y negativo $(98,9 \pm 0,6 \% ; p=0,051)$. Durante el Test del Aire, la SpO2 de los pacientes con test positivo fue más baja $(93,3 \pm 2,0 \%$ ) que en los pacientes con test negativo $(97,9 \pm 0,7 \% ; \mathrm{p}<0,0001)$. El ultrasonido pulmonar detectó atelectasias en 71 de los 88 pacientes (prevalencia de $81 \%$ ). De los pacientes con atelectasias observada con la ecografía, 65 tuvieron test positivos y 6 test negativos. La figura adjunta muestra dos ejemplos, uno con test positivo y otro negativo. El análisis ROC determinó un área bajo la curva ROC de 0,95 (Intervalo de Confianza 95\% entre 0,92 y 0,99) para detectar atelectasias con el Test del Aire tomando las imágenes de ecografía como referencia.

Conclusiones: El Test del Aire es una forma sencilla y no invasiva para diagnosticar el shunt inducido por atelectasias en pacientes pediátricos anestesiados.

https://doi.org/10.25237/congresoclasa2019.77 